\title{
Public University Models for Education - from Innovation to Entrepreneurship
}

\author{
ONeill, Peter; Kimberley, Nell and Teng, Chih Wei \\ Department of Management, Monash University, Melbourne Australia.
}

\begin{abstract}
The management of Australian public universities has changed dramatically over the last two decades with the decrease in public funding across teaching and research sectors. This has forced a strategic repositioning of universities and likewise a rethink on value generation and its translation into various revenue streams. The aim of this paper is to provide an analysis of current government innovation policy and university capabilities to support the translation of innovation, and in so doing explore the possibilities of a Quadruple Helix innovation approach to building new models for education. The paper begins by examining the significant role innovation plays in developing economic wealth, and a discussion of the triple helix framework that identifies the complex collaborative relationships between universities, government and industry. The development of a Quadruple Helix Innovation Model, which places the user at the centre of the relationship, highlights the importance of capabilities in the transmission mechanisms driving innovation. We argue that the measurement of appropriate capabilities formed through collaborations amongst key stakeholders will be critical to new business models. Universities are encouraged to embrace the user value driven business models to provide the innovation, execution and disruption necessary to quadruple the impact on national growth.
\end{abstract}

Keywords: University, Entrepreneur, Innovation, Business Model, Quadruple Helix, Empirical. 


\section{Introduction}

Innovation and entrepreneurial activities are recognised engines of long-term economic growth (Wang, Peng, \& Gu, 2011). Innovation results in continuous improvement and sustained competitiveness against on-going imitation by competitors, introduction of newer products/services and obsolescence (Rubera \& Kirca, 2012). However, the capitalization of benefits and externalities associated with innovation is not limited to the investing company but also society at large, e.g. commercializing novel pharmaceutical drugs result in career opportunities, better collaboration on new knowledge and opportunity for leverage into newer areas (PISG, 2008). Entrepreneurial activities may result in a substitution effect where older firms with less potential are replaced by newer and more successful firms (2007).

The recent Australian Government's National Innovation and Science Agenda (Innovation Agenda, DoPMC, 2015) actively seeks to capitalize upon the nation's innovation and entrepreneurship from public universities, as well as cultivate future Australian innovators through a revision of the junior and middle school's education curriculum. To enable this agenda, the literature postulates the existence of a collaborative relationship between universities/research-institutes, industry, government and civil society, known as the quadruple helix $(\mathrm{QH})$ framework. The $\mathrm{QH}$ framework has been used to articulate knowledge sharing, direct research activity, provide a lens to understand the complementary/synergistic nature between different stakeholders, and drive higher economic growth rates (Afonso, Monteiro, \& Thompson, 2012). Research application of the quadruple helix framework can assist stakeholders in focusing the innovation process more effectively to trigger and deploy creative capabilities faster and with greater effect (e.g. to respond to external or internal opportunities for new ideas, processes or products).

- To reconnoiter this agenda our research paper seeks to:

- Explore the transformational state of Australia's leading public universities (Go8) into entrepreneurial universities

- Compare current metrics that evaluate the state of university innovation/entrepreneurship within a $\mathrm{QH}$ framework.

\section{Literature Review}

The translation and commercialization of university research are widely acknowledged by both policy-makers and scholars as being an important driver of innovation, economic growth, employment, and solutions for global challenges (e.g. European Commission, 2014). The resource-based Quadruple Helix (QH) literature provides us with a lens and a language to explain how these processes occur. 


\subsection{Quadruple Helix (QH) Literature}

The triple helix model is a meta-model, that advocates for regions of translation which could enable couplings between the active systems of Government, University and Industry (Helms \& Heilesen, 2011). At a strategic level it assumes a top-down approach based on the contributions of experts from each of the systems. Building on Etzkowitz et al. (2007), Arnkil et al. (2010) added "the user" as the actor at the centre of the helix, giving rise to a set of innovation models that have four interacting components and thus a quadruplet. In contrast to the top-down triple helix meta-models, the $\mathrm{QH}$ models recognize that non-expert citizens acting as users or consumers actively participate in the co-production of new knowledge and new products. As yet, there is no universally accepted definition of the QH concept. Figure 1 shows a simplified form of the $\mathrm{QH}$ model, where all four "systemic actors" are broadly defined, e.g. user involvement in development. While relationships exist between each "actor", e.g. administrative, cultural, and economic, users can also be viewed in terms of a particular human need.

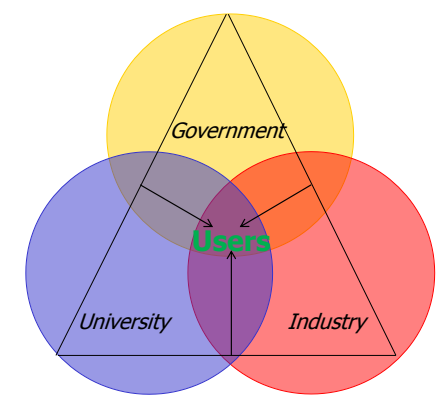

Figure 1 A Simple Quadruple Helix Model of Innovation (adapted from Arnkil, 2010)

Building on the work of Arnkil et al. (2010), we postulate a variant of the QH model combining roles, relationships and dependencies between government, business and educational institutions that is constantly undergoing changes in structure, content and function (see Figure 2). 


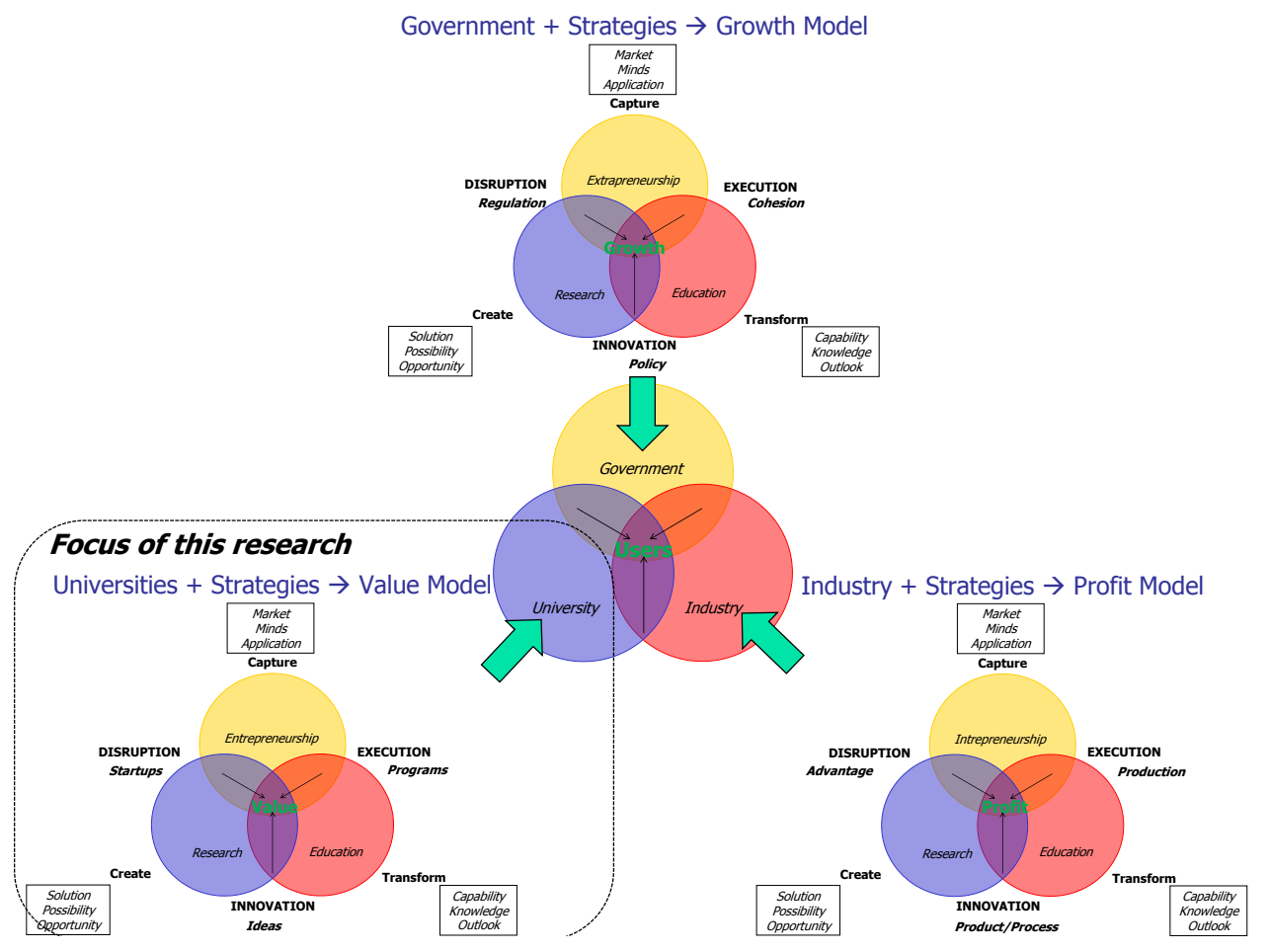

Figure 2. Macro Quadruple helix innovation model

The purpose of this variant is to reflect the operationalization of the Innovation Agenda (DoPMC, 2015) from a knowledge institution (university) point of view. In this $\mathrm{QH}$ structure, universities would be developing services (e.g. courses and learning objects), supporting user involvement in the development of products, collecting information about users, and supporting the dissemination and sharing of products. Government would support research, development, networking, knowledge dissemination as well as be the end user of resultant technologies. Industry would support research and development activities, make use of all available know-how in implementing commercial solutions, and collect information on user needs. In both industry-centred and government centred models, users would contribute experiences, generating ideas, and be involved in the development and implementation of innovations (entrepreneurship).

Of course, the traditional roles of government (e.g. regulation), and industry seeking profit (e.g. via disruptive advantage), are still taking place and are part of the relational dynamic. However, due to the changes in the global economy, these roles are constantly undergoing changes. For example, the primary objective of the Innovation Agenda (DoPMC, 2015) is to enable a societal innovation ecosystem within which all "actors" have a means to interactively improve the growth, value and leverage of "final-users". The purpose of the 
agenda is to establish frameworks for interaction, and then let actors work towards solutions. However, entrepreneurial-actors within the Australian ecosystem are concerned with consequences of risk taking (bankruptcy) and lack of a sizable consumer market. To minimise these risks entrepreneurial-actors choose to commercialize or relocate operations to the United States or Europe, resulting in a cycle of bounded capability. To address this, the Australian government has pledged to expand its role from a patron to a consumer of research. In this way, the innovation policy platform moves from a tool for developing the agenda to a systemic process for final-user implementation/consumption.

\subsection{Research Questions}

To address the research aims, this paper proposes the following questions:

RQ1: What entrepreneurial capabilities currently exist within Australia's Go8 Universities that support a QH framework?

RQ2: What metrics are needed to evaluate university entrepreneurial capabilities in a $\mathrm{QH}$ framework?

\section{Methods}

Against the context of the Australian Government's Innovation Agenda (DoPMC, 2015), our Research Questions seek to provide an insight into the strategic capability of public universities within a $\mathrm{QH}$ framework of innovation. The availability of data for these purposes is always problematic due to the complexity of obtaining primary information from a vast array of public institutions (i.e. universities). A secondary data quantitative research design was thus deemed appropriate for this exploratory paper due to the lack of research into the role public universities play in the conceptualisation of the $\mathrm{QH}$ framework. To that end we accessed a variety of Australian government longitudinal panel data sets that have been collected from the Australia's Go8 Universities between 2002-14 from the Department of Education as well as the Department of Industry, Innovation and Science. A longitudinal approach is appropriate for this paper because the approach allows trends between implementation and outcomes to give a more systemic view of relationships between policy input and translated innovation output.

The reports we accessed attempt to capture research commercialization of publicly funded Australian universities in terms of:

- inputs (e.g. revenue streams student fees and research, revenue from active licenses and commercial contracts)

- activities (e.g. research expenditure, and assigned manpower to commercialization activities, number of research consultancies)

- $\quad$ outputs (e.g. startups, license agreements and (provisional) patents filed). 
Even though the NSRC strives to present a holistic view of the University sector's efforts to commercialize its research, the survey is not without its flaws. Firstly, some data are missing, perhaps due to the difficulty, size and complexity of these organizations (Litan, Wyckoff, \& Fealing, 2013), and perhaps an unwillingness to disclose information e.g. expenditures associated with innovation and commercialization. Evidence of such discrepancies can be found in the following years; 2011 where a number of universities (UoS, UoM, UWA and UoA) did not report any research expenditure, and in 2012 where the UoQ did not report any information on royalties, patents or consultancies. Therefore, in order to derive meaningful information, methods of interpolation using the average of the prior and subsequent year's figures were used to complete the dataset. Secondly, the NSRC 2013-2014 report states that while the survey provides longitudinal data to capture trends and key data sets, much of the information gathered does not yet provide enough detail or depth to support micro decision making. However, the comparative data assembled here does support the need for more than a policy agenda.

\section{Findings}

To examine the current status of Go8 Universities in a QH framework, we have assembled in Table 1, a collection of the various core university data from 2008-14. We have structured this across proxies for key dimensions of the QH (Education activity, Research activity, Entrepreneurial engagement), the linking proxies across each of these (Innovation, Disruption, and Execution of Entrepreneurial Programs), and finally tangible Value created.

What we see from Table 1 is that education and research activity (indicated by revenues) are very strong, and in all but one case education dominate, and in the case of UoA by a factor of almost $\mathrm{x} 2$. In terms of entrepreneurial engagement there appears to be evidence that research contracts far outweigh consulting contracts to the broader (industrial) community. This data tends to confirm that the research focus of Australia's Go8 Universities is internally driven by discovery as opposed to application.

With regard to innovation, there is strong evidence of the links between knowledge and research, indicated by the number of patents/provisions filed and number of active licenses. However, there is evidence that Australian institutions underperform compared to their international counterparts, the UK, Canada and the US, for invention disclosures per \$US100m research expenditure. For example the number of invention disclosures per \$US100m research expenditure in Australia was 28.8 in 2011, compared with the UK (43.7), Canada (41.6), the US (35.8) and Europe (28.4) (DIISRTE, 2012). Also the number of Licenses, Options and Assignments executed per \$US100m research expenditure by Australian institutions at 8.3, is less than the 13.2 in Canada, 10.6 in Europe and 9.9 in the US. 
Start-ups as a proxy for disruptive activity are also very weak. Australian start-up companies formed per $\$$ US $100 \mathrm{~m}$ research expenditure have gradually declined from a peak of 2.2 in 2001 to less than 0.5 in 2013. The data in the UK and Canada showed a similar decline over the same period, but the number was much higher at 2.8 in the UK in 2010, 3.2 in Europe and at 1.6 in Canada in 2011. The US has maintained a stable rate of start-up company formation per $\$ \mathrm{US} 100 \mathrm{~m}$ research expenditure at around 1.1 over the last decade. In terms of tangible value created, the top five of Australia's Go8 Universities generate healthy revenue in excess of AU\$ 1 Billion per year, with the bottom three close to that mark. The data also suggests that less than $10 \%$ of this revenue is from sources other than government, and that the motivation for actively seeking this external revenue is very small.

In the case of Execution of Entrepreneurial Programs, it seems that Australia's Go8 universities generally do not see producing entrepreneurs as a major part of their role and as a result, do not significantly invest in programs to create entrepreneurs to the same degree as universities internationally. 


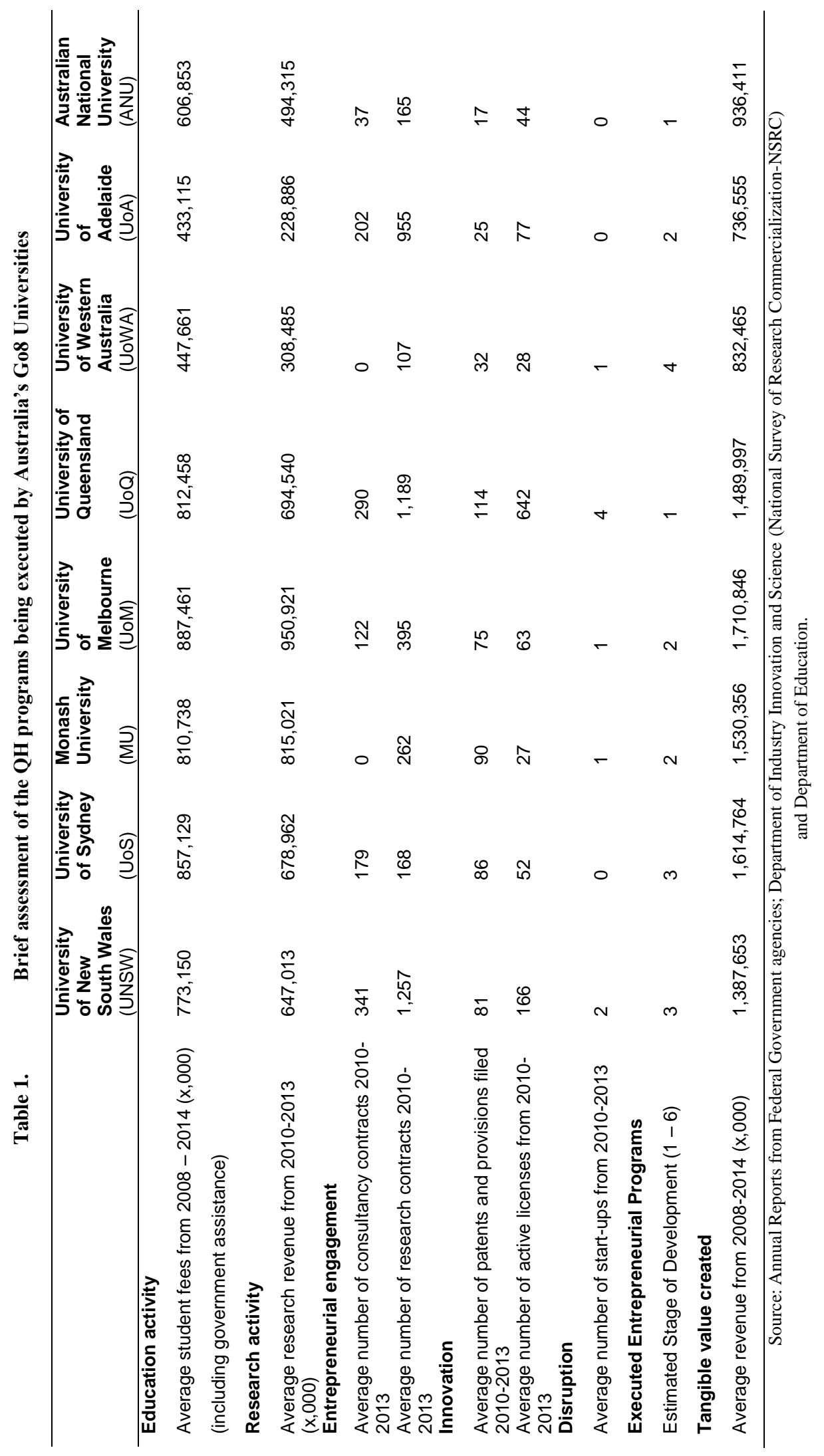




\section{Discussion}

We sought to answer two questions in this brief paper. In RQ1 we asked; What entrepreneurial capabilities currently exist within Australia's Go8 Universities that support a QH framework?

Drawing on the QH and Table 1, we suggest in Table 2 that Australia's Go8 Universities show demonstrable capability across the linking mechanisms of the Helix, albeit to varying degrees. However, we believe what's missing are the research and education capabilities necessary to develop the entrepreneurship capabilities required from the Government's Innovation Agenda.

From a teaching and learning perspective, these entrepreneurship capabilities need to be student-centred rather than teacher-centred. Moreover, the nature of learning should move away from traditional classroom teaching to short courses and experiential approaches that expose users to a rigorous, innovative, open and relevant curriculum. These approaches have the potential to develop both knowledge and skills in the application of innovative knowledge to entrepreneurial outcomes, along with opportunities to work closely with alumni, industry representatives and entrepreneurs in residence.

\begin{tabular}{ccccccc}
\hline Research & LINKS & Entrepreneurship & LINKs & Education & LINKS \\
\hline \multicolumn{3}{c}{ DISRUPTION } & \multicolumn{3}{c}{ EXECUTION } & INNOVATION \\
\hline Create & Capture & Transform \\
\hline MISSING & AVAILABLE & MISSING & AVAILABLE & MISSING & AVAILABLE \\
\hline Possibility & Startups & Markets & Edu.Programs & Capability & Idea.Patent \\
Opportunity & & Mindset & & $\begin{array}{c}\text { Knowledge } \\
\text { Outlook }\end{array}$ \\
Solution & & Applications & & Ond
\end{tabular}

Table 2.

Quadruple Helix Metrics Available / Missing

In RQ2 we asked; What metrics are needed to evaluate university entrepreneurial capabilities in a $\mathrm{QH}$ framework?

While generally supportive of the Innovation Agenda, the Go8's current stance draws heavily from its research-intensive focus by asserting that discovery research has the greatest impact. Such motivation and resourcing must be reoriented to deliver value in a QH framework via intentional translation/commercialisation. We feel that while discussions around business model development or how to address conflicting business models are constructive; the bigger issue at hand is the determination of metrics relevant to the $\mathrm{QH}$ that can lead to change. 
From Table 2 we suggest some of the new metrics that should be considered in the measurement of capability under Research-Creativity, Education-Transformation and Entrepreneurial-Capture.

\section{Conclusions}

We have used an existing Federal Government reporting/evaluation structure as a starting point to the measurement of the $\mathrm{QH}$ concept framework.

Though convenient and less disruptive, this approach will not result in the desired QH effect due to the risk of reinterpreting data while hoping for a new outcome. There must be first and foremost appropriate methods to capture the particularities and desired capabilities, and confronting the disruption that will bring about change and improvement. Measurements of the proposed $\mathrm{QH}$ framework must adequately reflect the different capabilities of an entrepreneurial university while capturing the universities' interaction between resources from industry, government and users. Our proposed capabilities structure link closely to the proposed $\mathrm{QH}$ concept framework to develop a more holistic measurement for the entrepreneurial university. Knowing what the desired outcomes are will provide a template for the strategic outlook required, improved resource planning/utilisation, and reward schema that apply equally across the academies of education, research and entrepreneurship.

\section{References}

Afonso, O., Monteiro, S., \& Thompson, M. (2012). A Growth Model for the Quadruple Helix. Journal of Business Economics and Management, 13(5), 849-865.

Arnkil, R., Järvensivu, A., Koski, P., \& Piirainen, T. (2010). Exploring Quadruple HelixOutlining user-oriented innovation - Final Report on Quadruple Helix Research for the CLIQ project (pp. 1-131). Tampere: Work Research Centre, University of Tampere.

DIISRTE. (2012). The National Survey Of Research Commercialisation 2010-2011 Canberra: Department of Industry Innovation Science Research and Tertiary Education, Commonwealth of Australia.

DoPMC. (2015). National Innovation and Science Agenda - Welcome to the Ideas Boom. Canberra: Department of the Prime Minister and Cabinet, Commonwealth of Australia.

Etzkowitz, H., Dzisah, J., Ranga, M., \& Zhou, C. (2007). The triple helix model of innovation a University-industry-government interaction. Tech Monitor, 14-23.

European Commission. (2014). Horizon 2020 - The EU Framework Programme for Research and Innovation. Brussels: https://ec.europa.eu/programmes/horizon2020/en/h2020-sections. 
Helms, N. H., \& Heilesen, S. B. (2011). Framing Creativity - User-driven Innovation in Changing Contexts. (http://www.eurodl.org/materials/special/2011/Helms_Heilesen.htm), 1-14.

Litan, R. E., Wyckoff, A. W., \& Fealing, K. H. (2013). Capturing Change in Science, Technology, and Innovation: Improving Indicators to Inform Policy. Washington, D.C: National Research Council.

PISG. (2008). Final Report (pp. 112 pages). Commonwealth of Australia: Pharmaceuticals Industry Strategy Group.

Rubera, G., \& Kirca, A. H. (2012). Firm Innovativeness and Its Performance Outcomes: A Meta-Analytic Review and Theoretical Integration. Journal of Marketing, 76, 130-147.

Vallini, C., \& Simoni, C. (2007). Managing University Support to Entrepreneurship and Entrepreneurs. Oxford Journal, 6(1), 1-17.

Wang, H., Peng, Z., \& Gu, F. (2011). The Emerging Knowledge Governance Approach within Open Innovation: Its Antecedents Factors and Interior Mechanism. International Journal of Business and Management, 6(8), 94-104. 